\title{
A Comparison of Effects of Ambient Pressure on the Atomization Performance of Soybean Oil Methyl Ester and Dimethyl Ether Sprays
}

\author{
H.J. Kim', S.H. Park' ${ }^{2}$ M.S. Chon ${ }^{3}$ and C.S. Lee ${ }^{1^{*}}$ \\ 1 Department of Mechanical Engineering, Hanyang University, 17 Haengdang-dong, Seongdong-gu, Seoul 133-791 - Korea \\ 2 Graduate School of Hanyang University, 17 Haengdang-dong, Seoungdong-gu, Seoul $133-791$ - Korea \\ 3 Department of Energy System Engineering, Chungiu National University, Chungiu - Korea \\ e-mail: junandjin@hanyang.ac.kr - psh7836@hanyang.ac.kr-mschon@cinu.ac.kr - cslee@hanyang.ac.kr \\ * Corresponding author
}

\begin{abstract}
Résumé - Comparaison des effets de la pression ambiante sur l'atomisation en "spray" de methylester d'huile de soja et de dimethyléther - Le but de cette étude est l'investigation expérimentale de l'effet de diverses pressions ambiantes sur les caractéristiques des sprays (issus d'un système "common rail") de methylester d'huile de soja (SME) et de dimethyléther (DME). La pression ambiante dépend de la chambre et sa valeur la plus haute peut monter jusqu'à $4 \mathrm{MPa}$. Pour comparer le développement de spray et la caractéristique d'atomisation, des images de spray de SME et DME à différentes pression ambiantes sont obtenues avec une caméra à haute vitesse à deux lampes de métal halide. Les caractéristiques du spray, comme la pénétration, la distance radiale maximale et le diamètre de spray, sont mesurées et analysées. De plus, le diamètre de Sauter (SMD) des deux carburants à différentes pressions est mesuré. On a constaté que, dans les mêmes conditions, la distance de pénétration du spray de SME est supérieure à celle du spray de DME. La pénétration axiale, la distance radiale maximale et le diamètre du spray décroissent quand la pression ambiante croît. Quand la pression ambiante croît, le SMD décroît et le spray de DME montre plus d'atomisation que celui de SME.
\end{abstract}

Abstract - A Comparison of Effects of Ambient Pressure on the Atomization Performance of Soybean Oil Methyl Ester and Dimethyl Ether Sprays - The purpose of this study is the experimental investigation of Soybean oil Methyl Ester (SME) and DiMethyl Ether (DME) spray characteristics injected through the common-rail injection system under various ambient pressures. A high pressure chamber that can be pressurized up to $4 \mathrm{MPa}$ was utilized for a change of ambient pressure. In order to compare the spray development and atomization characteristics, the images of SME and DME were obtained by using a high speed camera with two metal halide lamps under various ambient pressures in the spray chamber. From these spray images, the spray characteristics such as the spray penetration from the nozzle tip, maximum radial distance, and spray diameter were measured and analyzed. In addition, the Sauter Mean Diameter (SMD) of two fuels under ambient pressure was analyzed using the droplet measuring system. It was revealed that the axial distance of spray from the nozzle tip of the SME spray is longer than that of DME spray under same injection condition. The axial penetration, maximum radial distance, and spray diameter decreased when the ambient pressure in the chamber increased. As the ambient pressure increased, the SMD decreased and the DME spray showed a superior atomization performance compared to the SME spray. 


\section{INTRODUCTION}

The fuel spray characteristics assumed different aspects according to the various injection and ambient conditions such as injection pressure, energizing duration, injection mass, spray cone angle, ambient pressure, and ambient temperature in the combustion chamber. Particularly, in a High Speed Direct Injection (HSDI) diesel engine, spray characteristics are greatly influenced by the ambient conditions in the cylinder. In addition, the atomization and spray characteristics of fuel were directly influenced on the combustion performance and emission characteristics. Many studies on the diesel spray, SME and DME spray characteristics under various ambient conditions of high pressure and temperature have been conducted by researchers.

Paryi et al. (1996) conducted the investigation on the evolution of diesel spray under a high gas density by using high speed photography and phase Doppler anemometry. They reported that a spray cone angle was more influenced by a gas density than the injection condition. The experimental and numerical studies on the diesel spray penetration at a high pressure and temperature under various injection pressures were carried out by Abdelghaffar et al. (2007). They suggested that the diesel spray penetration length decreased with the increasing of an in-cylinder pressure, and tip penetration decreased due to the increase of vaporization rate at the high ambient gas temperature. Roisman et al. (2007) studied the experimental and theoretical investigations on the diesel spray penetration and cone angle at the ambient pressure in the chamber. Their work suggested that the spray penetration was determined by two major factors such as inertia of liquid/air mixture in the steady conical spray region and the particular conditions near the leading spray edge. The research on the vapor/liquid phase penetration and spray cone angle under ambient condition equivalent to an actual engine cylinder was conducted by Yamashita et al. (2007). They found that the vapor phase penetration increased but the penetration of rich mixture becomes shorter when the injection pressure increased.

Besides being the diesel spray characteristics as the ambient condition, investigations on alternative fuels for the diesel fuel have been actively advanced to solve the environmental pollution. Among many alternative fuels, Soybean oil Methyl Ester (SME) and DiMethyl Ether (DME), including a large amount of the oxygen molecular, can be produced with lower exhaust emissions, such as soot and particulate matter, compared to diesel fuel. These fuels are suitable for the compression ignition engine due to a high cetane number. Therefore, the SME and DME fuel are in the spotlight of representative alternative fuel instead of the diesel fuel.

However, the SME fuel has demerits such as the disturbance factor of atomization by a high viscosity, a problem in a coldstart due to crystallizing property, and the acidification during long-term storage. In the case of DME fuel, pressure is applied to convert the liquid phase at the atmospheric condition and can leak in the fuel supply system by low viscosity and bad lubrication (Sorenson et al., 1998). Also, the modification of the fuel supply system needs to directly apply to the diesel engine due to the melting property by reaction with rubber. In order to solve these problems, more studies are needed to clarify the spray characteristics of SME and DME due to the different fuel properties.

Fang et al. (2008) investigated that the experimental spray and combustion characteristics of diesel, biodiesel, and diesel-biodiesel blended fuels were analyzed by using visualization system in a small-bore HSDI diesel engine. They reported that the longer penetration and ignition delay were observed with more biodiesel content. Lee et al. (2005) suggested that the atomization performance fell off and the peak combustion pressure increased as the mixing ratio of biodiesel increased in their study on the atomization and combustion characteristics according to the mixing ratio of biodiesel blended fuel. The experimental investigations on the spray structure of diesel fuel and oxygenated fuel including DiMethyl Ether by using PIV method were studied by Wu et al. (2006). Kim et al. (2008a) carried out the comparison between the experimental and numerical study on the spray characteristics of biodiesel, DiMethyl Ether, and biodiesel-ethanol blended fuels. Also, they experimentally and numerically analyzed the spray characteristics of diesel and DME fuels under the high ambient pressure in different chamber shapes (Kim et al., 2008b). Sidu et al. (2001) and Li et al. (2001) studied the experimental study on the spray and evaporation characteristics of DME fuel in the constant volume combustion chamber. They revealed that the spray penetration and the spray angle decreased and increased with increasing ambient density, respectively. In addition, DME spray were much faster the evaporating process than diesel spray at high ambient temperature. However, the high viscosity of biodiesel fuel makes the needle lift slower. Also, the high density and bulk modulus of biodiesel fuel led to the higher injection velocity, longer penetration and narrower cone angle than the diesel fuel (Pogorevc et al., 2008; Desantes et al., 2009). The spray tip penetration of biodiesel increased and its spray cone angle decreased when the ambient pressure became lower. Also, the penetration more affected by the ambient pressure than the injection pressure (He et al., 2008).

Detailed information on the spray and atomization characteristics of DME and biodiesel fuel under the ambient condition in the constant volume chamber is limited and it has many uncertainties due to the insufficiency of analysis on the comparison between the overall spray characteristics of DME and biodiesel. Therefore, in this study, the experimental investigations were conducted by using high speed camera and droplet measuring systems for the analysis of SME and DME spray characteristics according to the injection conditions under various ambient pressures in the chamber. 
From these results, the spray development processes were observed and the spray characteristics such as the axial distance from the nozzle tip, the maximum radial distance and spray diameter at the bottom view were measured from spray images according to the time after the start of the injection. In addition, the atomization performance of SME and DME fuel compared and analyzed from the local Sauter Mean Diameter (SMD) by using the droplet measuring system.

\section{EXPERIMENTAL APPARATUS AND PROCEDURES}

In order to investigate the atomization characteristics, the visualization and droplet measuring systems were composed of the spray visualized system, spray measuring system, and the data acquisition system as shown in Figure 1. Two parallel linked high pressure pumps were utilized to inject a high pressure spray. To use DME fuel of a liquid phase, DME fuel of gas phase in the fuel tank was pressurized to $1 \mathrm{MPa}$ by a nitrogen gas. Liquefied DME was supplied to a single hole injector with $0.3 \mathrm{~mm}$ of hole diameter through a commonrail. Test injector was controlled by an injector driver (TEMS, TDA-3200H). A high speed camera (Photron, Fastcam-APX RS) and two metal-halide lamps (Photron, HVC-SL) were used to analyze the spray characteristics of SME and DME fuels. The injection signal of an injector and shutter signal of the high speed camera were synchronized by a digital delay/pulse generator (Berkeley Nucleonics Corp, Model 555). The high speed camera was set to a shutter speed of $1 / 20000 \mathrm{~s}$, and a frame rate of $10000 \mathrm{fps}$, and high resolution of $512 \times 512$.
The droplet measuring system, called a Phase Doppler Particle Analyzer (PDPA) system, consists of an Ar-ion laser with a $5 \mathrm{~W}$ maximum power, a transmitter, a receiver, and a signal analyzer in order to investigate the fuel atomization characteristics including spray diameter. Ar-ion laser as a light source has a laser beam diameter of $1.4 \mathrm{~mm}$ and two wave lengths of $514.4 \mathrm{~nm}, 488 \mathrm{~nm}$. Specifications of the high speed camera and PDPA system were shown in Table 1.

TABLE 1

Specifications of experimental apparatus

\begin{tabular}{c|c}
\hline \multicolumn{2}{c}{ High speed camera } \\
\hline Light source & Metal halide lamp \\
\hline Frame rate & $10000 \mathrm{fps}$ \\
\hline Shutter speed & $1 / 20000 \mathrm{sec}$ \\
\hline Resolution & $512 \times 512$ \\
\hline \multicolumn{1}{c}{ PDPA system } \\
\hline Light source & Ar-ion laser \\
\hline Wave length & $514.5,488 \mathrm{~nm}$ \\
\hline Laser beam diameter & $1.4 \mathrm{~mm}$ \\
\hline Collection angle & $30^{\circ}$ \\
\hline Number of detected droplets & 5000 \\
\hline Laser output & $2.0 \mathrm{~W}$ \\
\hline Diameter subrange & $2-80 \mu \mathrm{m}$ \\
\hline
\end{tabular}

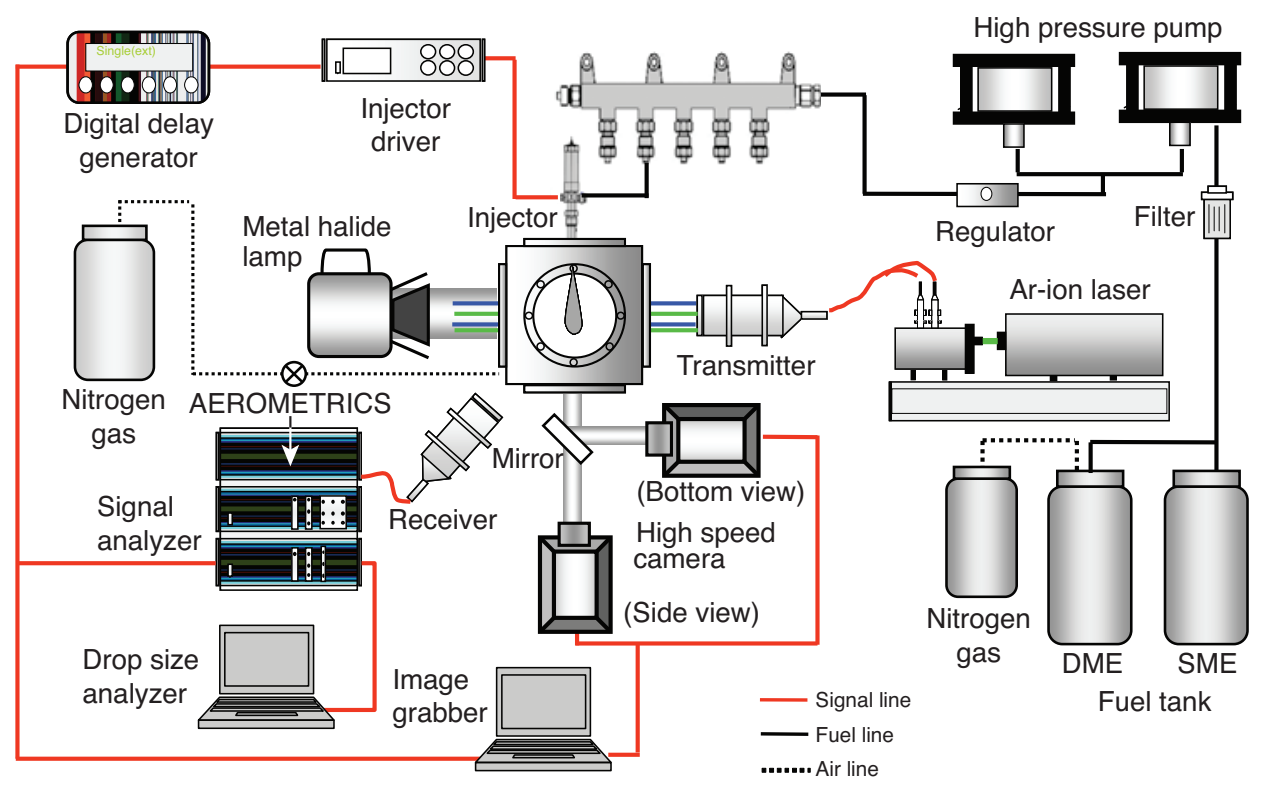

Figure 1

Schematics of spray visualization and droplet measuring systems. 


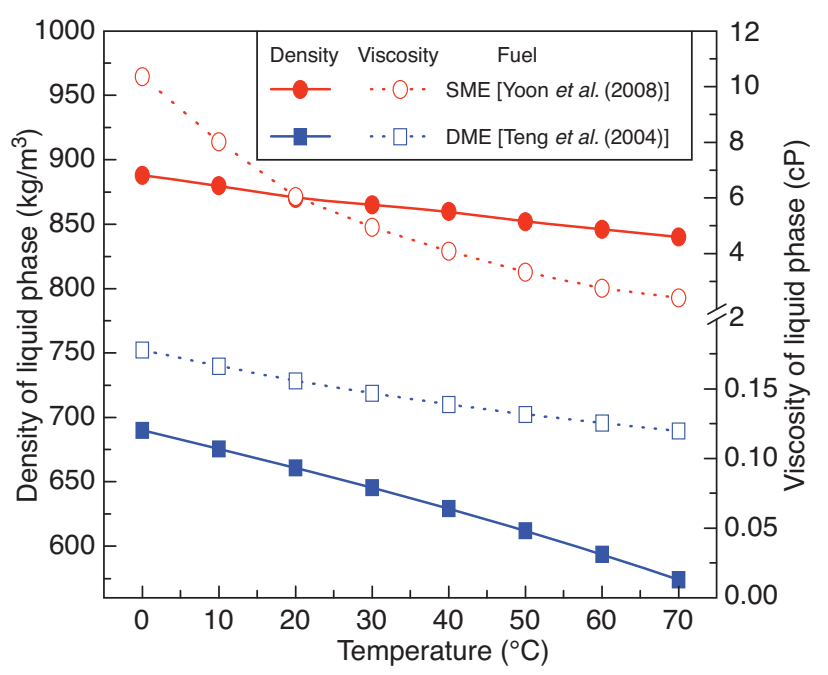

Figure 2

Density and viscosity of test fuels according to variation in temperature.

In this work, the injection characteristics and spray behavior under the various ambient pressures were investigated by using Soybean oil Methyl Ester and DiMethyl Ether. The properties of SME fuel were based on the experimental results investigated by Yoon et al. (2008). Also, Teng et al. (2001-2004) and Teng and McCandless (2005) carried out the numerical investigations of the thermodynamic characteristics of the liquefied DME on the basis of developed equations for the commonly used thermo-physical properties. Figure 2 shows the viscosity and density of SME and DME fuel at the liquid phase according to the variation in temperature. As the temperature increased, a density and viscosity of both fuels decreased. In addition, the density of SME fuel is higher than that of DME fuel and DME fuel has very low viscosity in comparison with SME fuel.

For investigating the injection characteristics, four hundred continuous injections were averaged for a test case according to the injection duration. Also, the injection delay was calculated by the time from the input of an electric signal at the injector till the start of the injection at the nozzle exit from spray images. Macroscopic spray characteristics, which obtained from a high speed camera, were analyzed from spray images of side view and bottom view type. The spray characteristics such as the axial distance from the nozzle tip, the maximum radial distance, and spray diameter in the bottom view were defined as illustrated in Figure 3. For investigating the microscopic spray characteristics, measurement points were selected at $10 \mathrm{~mm}$ intervals from a distance of $20 \mathrm{~mm}$ at the nozzle tip to $60 \mathrm{~mm}$ toward the axial direction. After the ending of the measurement at one point, the remaining gas and fuel in the chamber were exhausted by the compressed nitrogen gas for the accurate experiment. Also, the diameter sub-range was set from $2 \mu \mathrm{m}$ to $80 \mu \mathrm{m}$, and approximately 5000 droplets were averaged at each measuring point. Visualization and droplet measuring experiments were conducted under various ambient pressures of 1,10 , $20 \mathrm{bar}$, and injection duration of $1.2 \mathrm{~ms}$. An ambient gas pressure was controlled by nitrogen gas. Detailed experimental conditions were illustrated in Table 2.

TABLE 2

Experimental conditions

\begin{tabular}{c|c}
\hline \multicolumn{2}{c}{ Spray visualization } \\
\hline Injection pressure & $500,700 \mathrm{bar}$ \\
\hline Ambient pressure & $1,10,20 \mathrm{bar}$ \\
\hline Energizing duration & $1.2 \mathrm{~ms}$ \\
\hline Ambient temperature & $293 \mathrm{~K}$ \\
\hline
\end{tabular}

\begin{tabular}{c|c}
\hline \multicolumn{2}{c}{ Droplet measurement } \\
\hline Injection pressure & $700 \mathrm{bar}$ \\
\hline Ambient pressure & $1,10,20 \mathrm{bar}$ \\
\hline Energizing duration & $1.2 \mathrm{~ms}$ \\
\hline Ambient temperature & $293 \mathrm{~K}$ \\
\hline
\end{tabular}

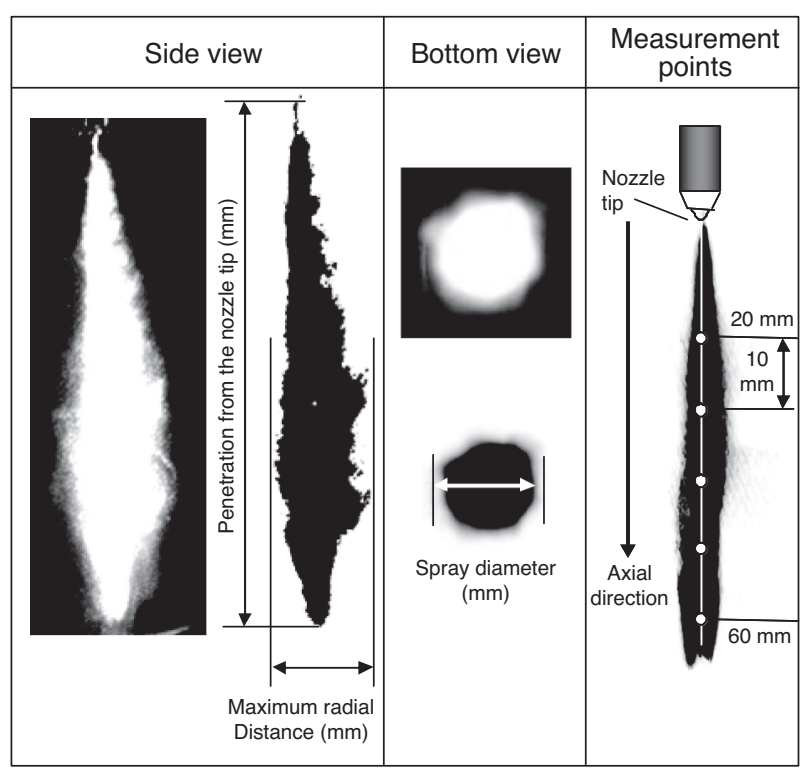

Figure 3

Definitions of spray characteristics and measurement points.

\section{RESULTS AND DISCUSSION}

\subsection{Injection Characteristics of SME and DME Spray}

The injection quantity according to the energizing duration and the injection delay were measured in order to analyze the 

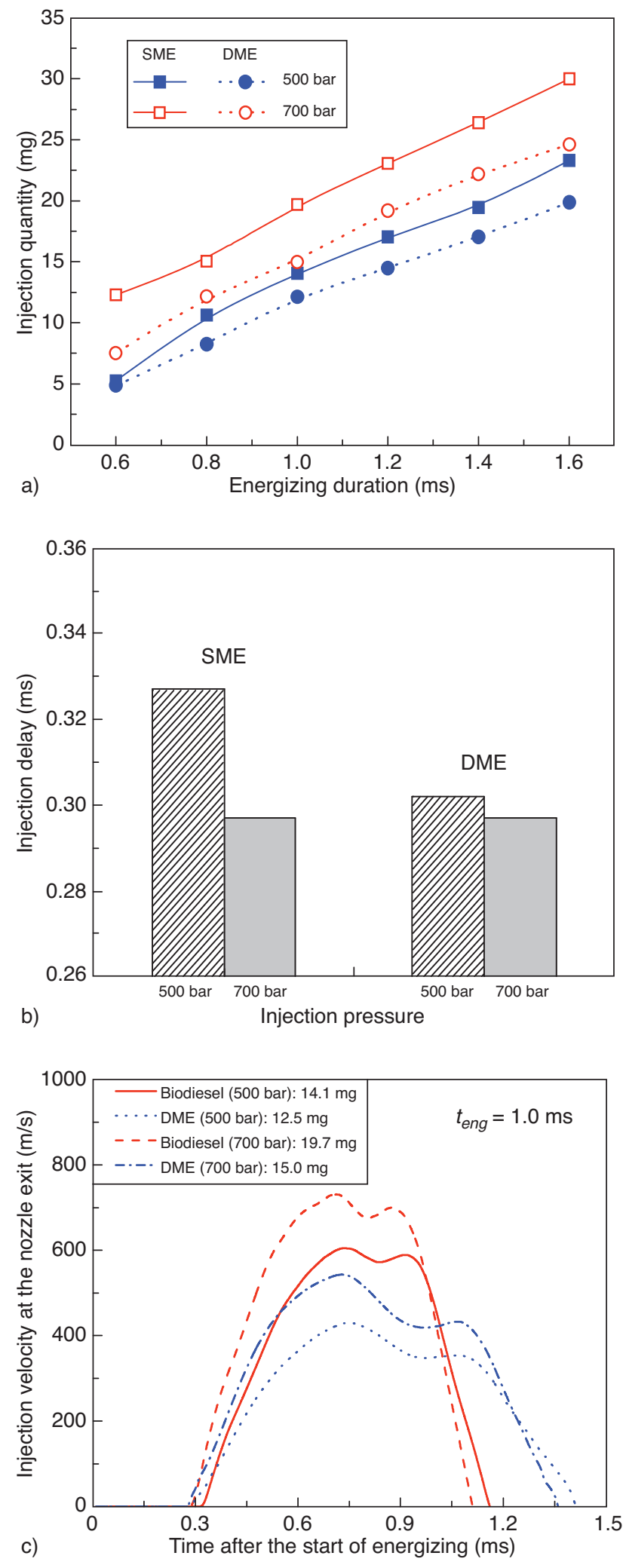

Figure 4

Injection quantity, delay and velocity according to the two fuels and pressure. a) injection quantity; b) injection delay; c) injection velocity (energizing duration $=1.0 \mathrm{~ms}$ ). injection characteristics of SME and DME spray. Figure 4a shows the injection quantity of SME and DME spray at 500 and 700 bar of injection pressure according to the energizing duration. As the injection duration increased, the injection quantity of two fuels shows a linear increase curve. The gap of injection quantity between the 500 bar and 700 bar of injection pressure showed a similar value regardless of the injection duration. In addition, it is known that the injection quantity of SME spray is larger than that of DME spray at all injection conditions because the DME fuel has a lower density than the SME fuel as can be seen in Figure 2.

The injection delay of SME and DME spray according to the injection pressure was illustrated in Figure 4b. The injection delay defined the time from the input of electric signal at the injector till the start of the injection at the nozzle exit. As can be seen in Figure 4b, the injection delay of SME spray at the 500 bar of injection pressure is longer than that of DME spray because of the friction between the fuel and nozzle in the injector by a high viscosity of SME fuel. However, the injection delay of SME and DME spray at the injection pressure of 700 bar shows an almost equal value because it can be guessed that the effect of fuel viscosity is lower than that of the faster velocity by a high injection pressure.

Figure $4 \mathrm{c}$ shows the injection velocities of the two fuels and injection pressure according to the elapsed time after the start of the energizing. On the basis of the Bosch method (Bosch, 1966), the injection rates were measured by an injection rate measuring system. In addition, the injection velocities of two fuels were calculated by the obtained information from the injected mass and injection rate. As the injection pressure increased, it tends to increase the injection velocities of two fuels. Also, the biodiesel fuel has higher peak of injection velocity than the DME fuel regardless of injection pressure but the DME fuel early jetted out of nozzle hole exit compared to the biodiesel fuel due to the low DME fuel viscosity. The injection duration increased with increasing injection pressure and biodiesel fuel showed a short injection period compared to DME fuel.

\subsection{Development Process of SME and DME Spray}

The development processes of SME and DME spray were analyzed from spray images obtained by high speed camera. Figure 5 shows the SME and DME spray images of $0.6 \mathrm{~ms}$ and $1.2 \mathrm{~ms}$ after the start of the injection according to the ambient pressure. As can be seen in Figure 5a, the spray development of two fuels in the side view was slow progress when the ambient pressure increased. This reason is the prevention of spray progress toward the axial and radial direction due to a high drag force caused by an increase of ambient pressure. In the case of spray images at $0.6 \mathrm{~ms}$ after the start of the injection, the development of DME spray is faster than that of SME spray, but the SME spray at $1.2 \mathrm{~ms}$ developed quickly compared to the DME spray. For this reason, it 


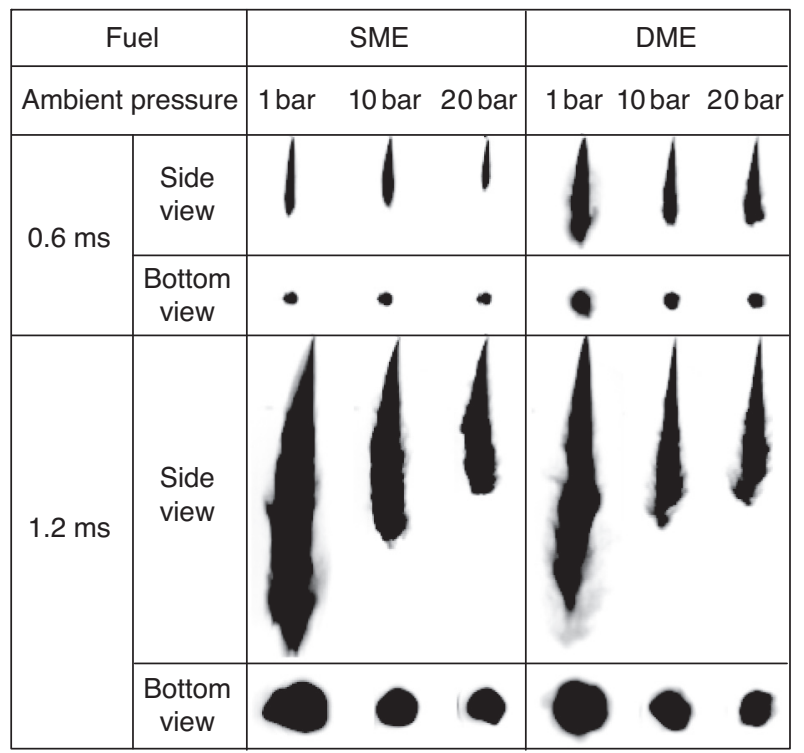

a) $P_{\text {inj }}=500$ bar

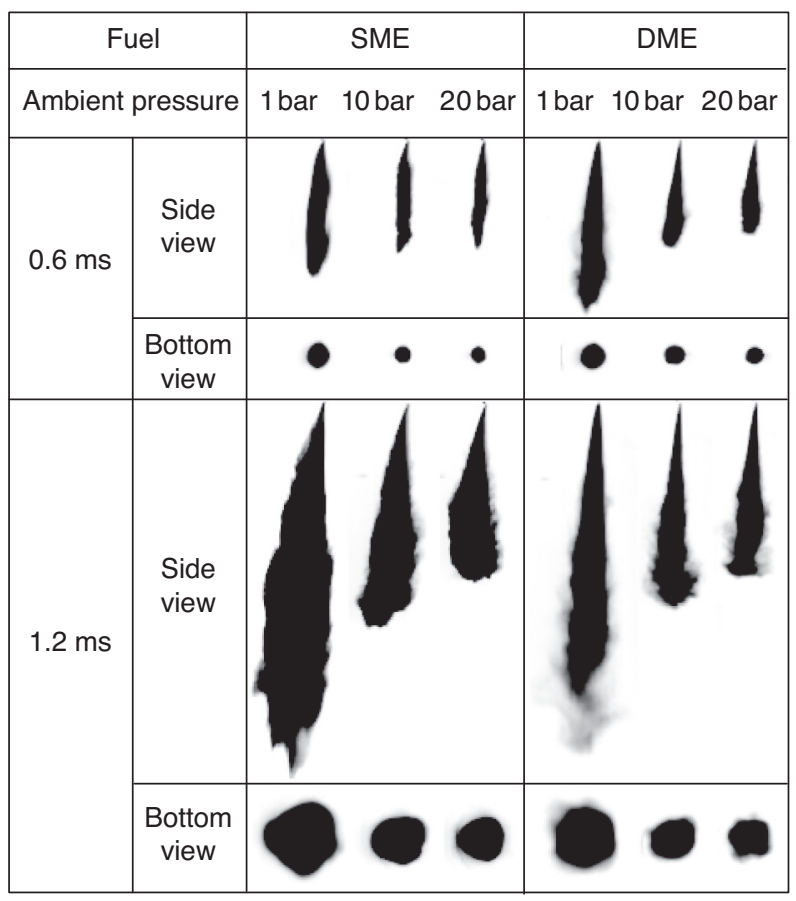

b) $P_{i n j}=700$ bar

Figure 5

SME and DME spray images of the 0.6 and $1.2 \mathrm{~ms}$ after the start of the injection according to the ambient pressure.

can be guessed that the DME spray has a short injection delay duration at the early stage of injection and the evaporation at the end region of spray actively occurred by the vaporization characteristics of DME fuel. In the bottom view, it is shown that the spray development of circular form become wider in proportion to the elapsed time after the start of the injection. As the ambient pressure in the chamber increased, the spread of spray development toward the outer region become slower by an increase of ambient density in the chamber.

Figure $5 \mathrm{~b}$ illustrates the comparison between the SME and DME spray development of $0.6 \mathrm{~ms}$ and $1.2 \mathrm{~ms}$ after the start of the injection at the injection pressure of 700 bar according to the ambient pressure. The entire spray development images at the injection pressure of 700 bar are longer and wider than that at 500 bar. The image of DME spray at the $0.6 \mathrm{~ms}$ after the start of the injection has a longer and wider spray development than that of SME spray due to the short injection delay duration by the low viscosity of DME fuel. On the other hand, the great difference between the SME and DME spray appeared from spray images of the $1.2 \mathrm{~ms}$ at the atmospheric condition $\left(P_{a m b}=1\right.$ bar). This is why the DME spray was affected by two factors of atomization at the spray tip and vaporization property. Also, the SME and DME spray at the ambient pressure of 20 bar show a similar developing length due to a weak influence of evaporation property of DME at a high chamber pressure. From the spray development in the bottom view, the SME spray has a wider circular development than DME spray because the droplets of DME spray actively break up and droplets after the breakup vaporized from the outer region of spray.

The outer spray line of SME and DME spray development process under the ambient pressure of 10 bar and 20 bar at the injection pressure of 500 bar was illustrated in Figure 6.

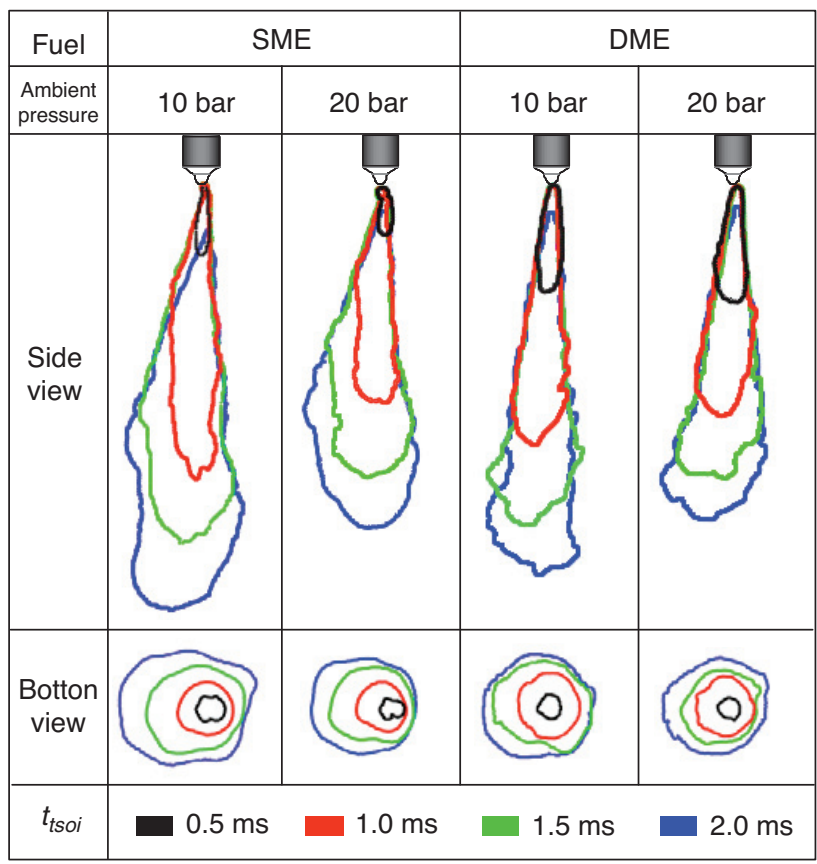

Figure 6

The outer spray line of SME and DME spray development process under the ambient pressure of 10 bar and 20 bar $\left(P_{i n j}=500\right.$ bar $)$. 
The spray development of two fuels makes a steady advance toward the axial direction as the time after the start of the injection elapsed. On the whole, the DME spray shows a long and narrow spray development, but the SME spray has a long and wide spray development. Also, the spray development at the ambient pressure of 20 bar makes slow progress toward the axial direction compared to the spray development at the ambient pressure of 10 bar due to the increase of ambient density in the chamber. It is known that the difference between the SME and DME spray in the side and bottom view appeared from the $1.5 \mathrm{~ms}$ after the start of the injection. This reason is because of the smaller injection quantity of DME spray and more evaporation of droplets after the breakup at the outer spray than those of SME spray.

\subsection{SME and DME Spray Characteristics}

Figure 7 shows the effect of the ambient pressure on the axial penetration from the nozzle tip of SME and DME spray at the injection pressure of 500 bar and 700 bar according to the time after the start of the injection. The axial arrival distances from the nozzle tip of two fuels get shorter when the ambient pressure increased. As the injection pressure increases, the penetration of two fuels spray increases by the high velocity at the nozzle exit regardless of the ambient pressure in the chamber. The penetration of DME spray is longer than that of SME spray at the early stage of the injection due to the short injection delay duration and a low viscosity of DME fuel property. However, this pattern reversed from the $0.6 \mathrm{~ms}$ after the start of the injection and then a gap between the SME and DME spray increased after an elapse of $0.6 \mathrm{~ms}$. In the ambient pressure of $1 \mathrm{bar}$, the fluctuation of the penetration of DME spray at the injection pressure of 500 bar and 700 bar repeatedly appeared from the $1.2 \mathrm{~ms}$ and $1.4 \mathrm{~ms}$ after the start of the injection, respectively. It can be guessed that this fluctuation of penetration occurred by the vaporization at the end region of spray.

The effect of the ambient pressure on the maximum radial distance of SME and DME spray at the injection pressure of 500 bar and 700 bar according to the time after the start of the injection was illustrated in Figure 8. As the injection pressure increased, the maximum radial distance increased because the droplets after breakup at the outer spray region advanced toward the radial direction by a drag force of the surrounding gas. In addition, the maximum radial distance of two fuels decreased when the ambient pressure increased due to a rise in ambient density in the high pressure chamber. In the early stage of the injection, the maximum radial distance of DME spray is longer than that of SME spray because the droplets of DME spray after many atomizations were rolled in the vortex at the outer spray. However, the increasing rate of maximum radial distance of DME spray slowed from $0.6 \mathrm{~ms}$ after the start of the injection, while the evaporation of droplets after the breakup took place at the outer region of
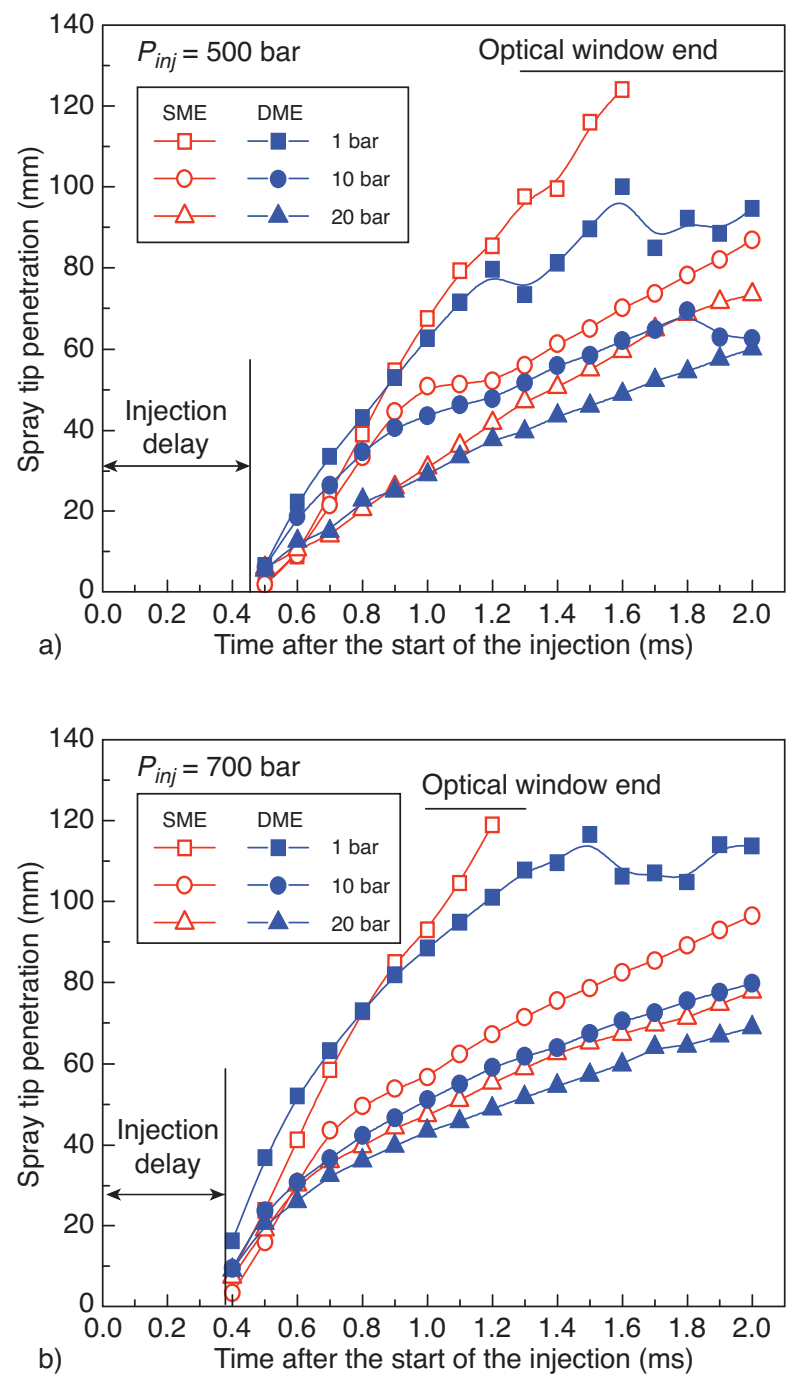

Figure 7

Effect of the ambient pressure on the penetration from the nozzle tip of SME and DME spray at the injection pressure of 500 bar a) and 700 bar b) according to the time after the start of the injection.

spray. The starting point of evaporation defines the beginning time of decrease of the maximum radial distance and it can be known that the starting point of evaporation of DME spray delayed when the ambient pressure increased as can be seen in Figure 8b.

Figure 9 represents the effect of the ambient pressure on the spray diameter in the bottom view of SME and DME spray at the injection pressure of 500 bar and 700 bar according to the time after the start of the injection. As indicated by results from the side view, the spray diameters of two fuels show the increase and decrease patterns, when the injection and ambient pressure increased, respectively. From these results, it can be known that the diffusion of fuel spray was disturbed by a high ambient density in the chamber. The 

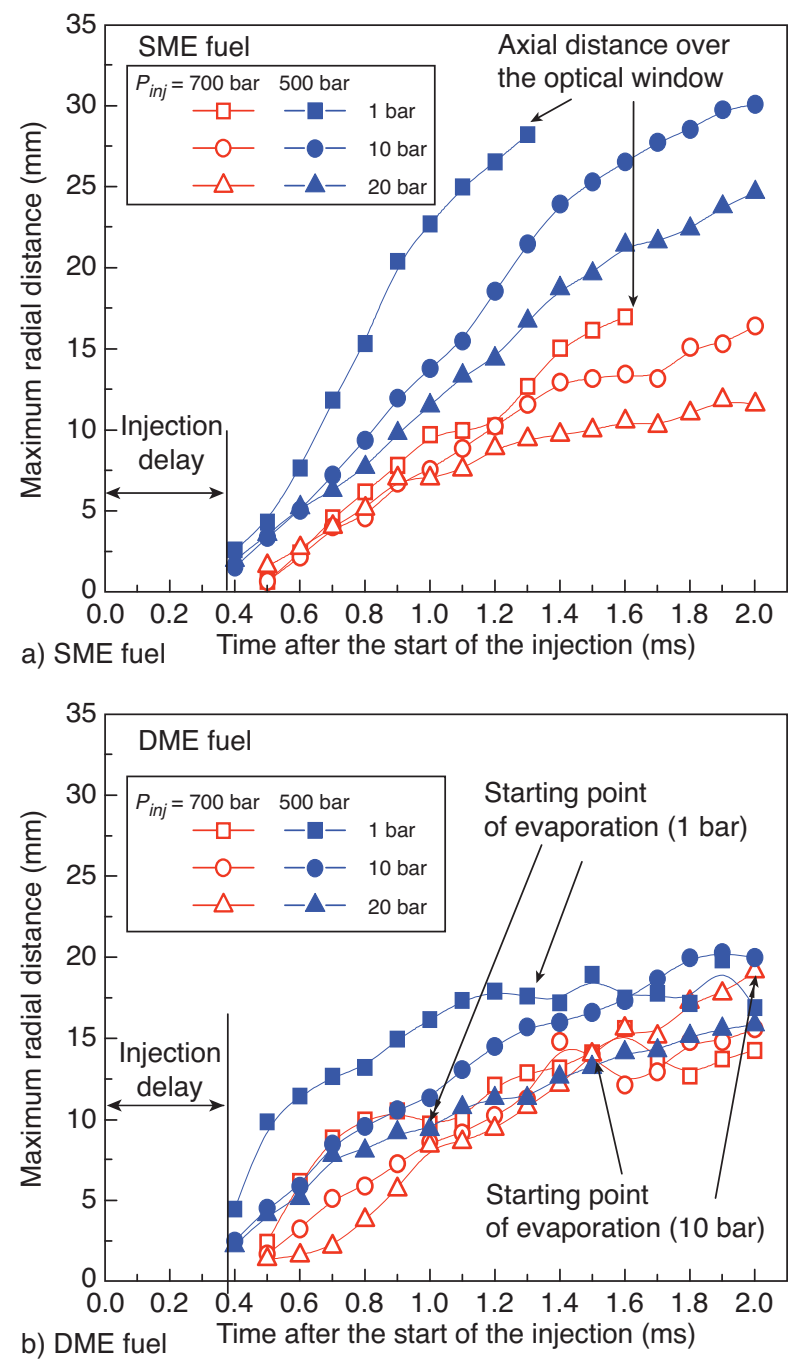

Figure 8

Effect of the ambient pressure on the maximum radial distance of SME a) and DME b) spray at the injection pressure of 500 bar and 700 bar according to the time after the start of the injection.
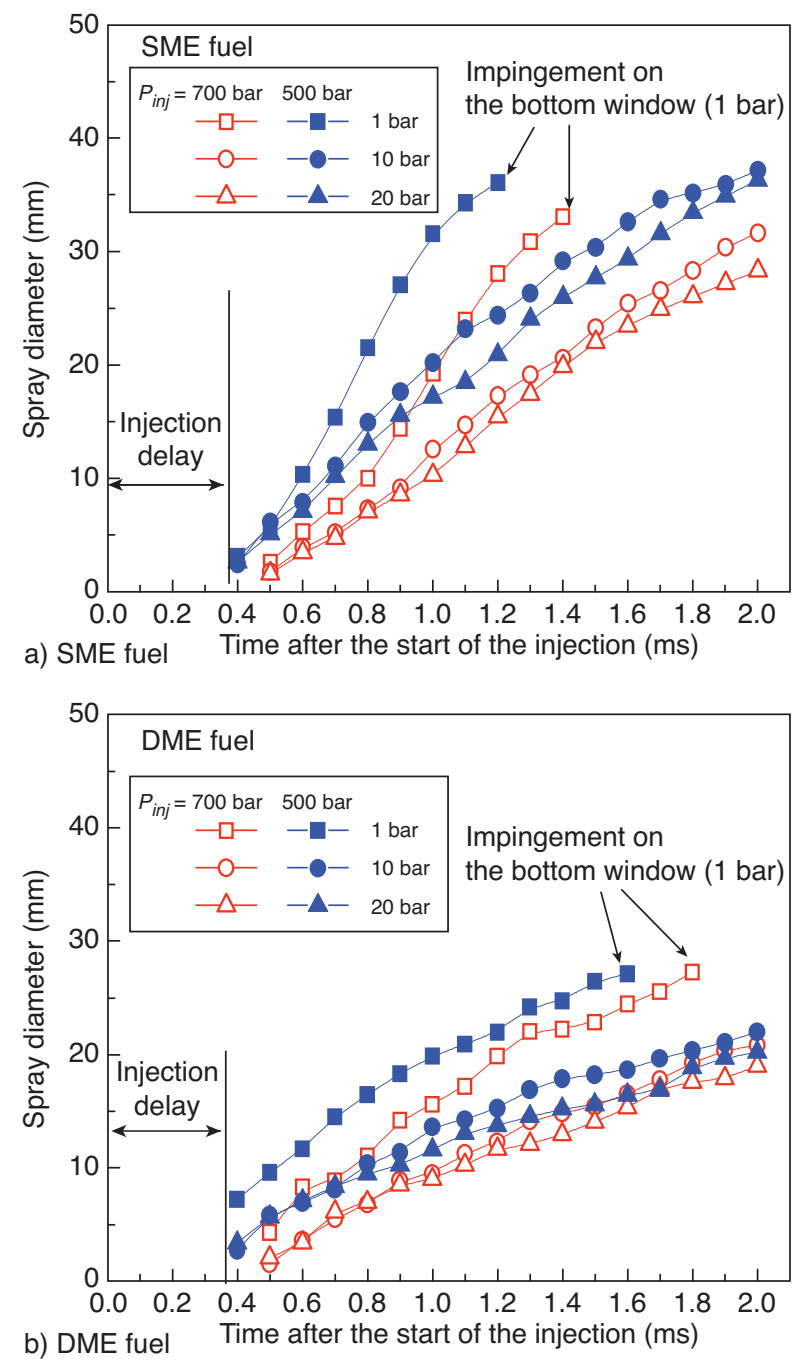

Figure 9

Effect of the ambient pressure on the spray diameter in the bottom view of SME a) and DME b) spray at the injection pressure of 500 bar and 700 bar according to the time after the start of the injection. spray diameter of SME fuel rapidly increased from the $0.6 \mathrm{~ms}$ after the start of the injection, but the slow increase pattern of spray diameter showed in the case of DME spray. These are why the breakup time of SME spray begins in the $0.6 \mathrm{~ms}$ by high viscosity of SME fuel and the evaporation of DME spray prevented the increase of spray diameter by a high vapor pressure of DME fuel.

\subsection{Atomization Characteristics of SME and DME Spray}

In order to compare the atomization characteristics of SME and DME spray under various the ambient pressures in the chamber, the SMD of both SME and DME sprays according to the distance of axial direction were measured and compared by using a droplet measuring system.

Comparison between the local SMD of SME and DME at the injection pressure 700 bar according to the ambient pressure was illustrated in Figure 10. Local SMD of two sprays decreased from the nozzle tip to the $30 \mathrm{~mm}$ of penetration. The increase and decrease of local SMD repeatedly appeared over the $30 \mathrm{~mm}$ of axial distance as can be seen in figure. It was conjectured that the decrease of local SMD was affected by a fast velocity at the nozzle exit and the collision and coalescence of droplets have an effect on the fluctuation of local SMD according the axial distance. The effect of ambient 


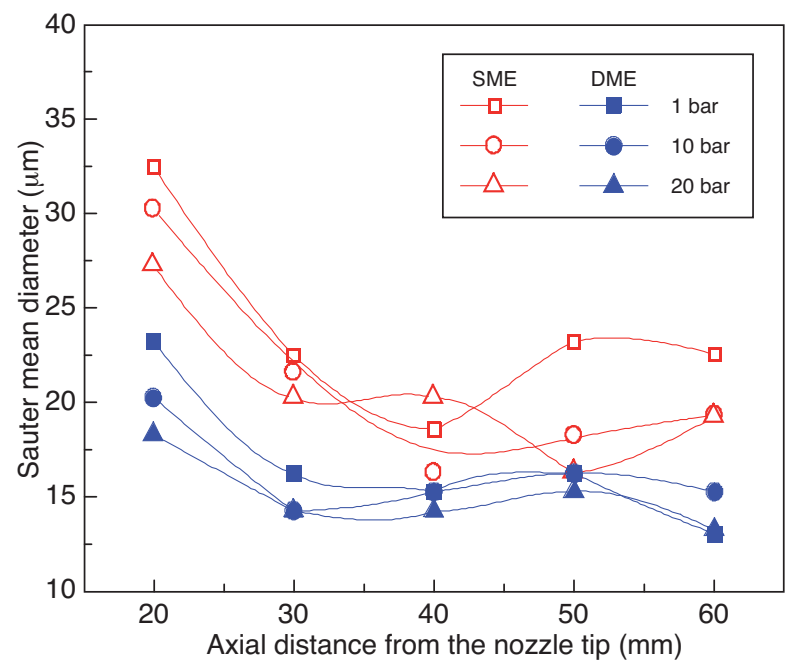

Figure 10

Comparison between the local SMD of SME and DME according to the ambient pressure $\left(P_{i n j}=700 \mathrm{bar}\right)$.

pressure on atomization of SME and DME spray showed that as the ambient pressure increased, local SMD of two sprays have decreasing patterns. The capillarity constants of DME and biodiesel fuel are $1.93 \mathrm{~mm}$ and $2.56 \mathrm{~mm}$ from its equation $(a=\sqrt{2 \sigma / \rho g})$, respectively. The capillarity constant value of DME fuel has the $75 \%$ of that of biodiesel fuel due to the lower surface tension compared to biodiesel fuel. Therefore, the lower capillarity constant of DME fuel makes the fast droplet breakup, especially the high injection pressure condition at the nozzle exit. Furthermore, it can be guessed that the small droplets after the breakup have great influence on the size of droplets at the each measurement points. Also, local SMD distribution of SME spray has the range from $20 \mu \mathrm{m}$ to $45 \mu \mathrm{m}$ and that of DME spray has the range from $10 \mu \mathrm{m}$ to $25 \mu \mathrm{m}$. Therefore, it can be judged that the DME spray has a superior atomization performance compared to the SME spray under the same injection condition regardless of the ambient pressure.

\section{CONCLUSION}

An experimental investigation on the comparison between the SME and DME spray under various ambient pressures was conducted by using the visualization and droplet measuring systems for analyzing the spray behavior and atomization characteristics. The spray behaviors such as a spray development process, spray tip penetration from the nozzle exit, a maximum radial distance, and a spray diameter were analyzed from the spray images obtained by a high speed camera. Also, the local SMD of two sprays according to the axial direction were measured and compared. The conclusions are summarized as follows:

- as the energizing duration increased, the injection quantity of SME and DME fuel shows a linear increase and the injection quantity of SME spray is larger than that of DME spray. Also, the injection delay of SME spray at 500 bar of injection pressure is longer than that of DME spray, but the injection delay of SME and DME spray at the injection pressure of 700 bar shows a similar value;

- spray developments of two fuels are slower when the ambient pressure increased. In the early stage of injection, the development of DME spray is faster than that of SME spray, but the SME spray at $1.2 \mathrm{~ms}$ of the time after the start of the injection quickly developed compared to the DME spray;

- spray tip penetrations and maximum radial distances of two fuels increase as the injection pressure increases but they decrease, when the ambient pressure increases. The penetration of DME fuel under the atmospheric condition repeatedly showed the increase or decrease of that from the starting point of evaporation. In the spray at the bottom view, the spray diameter becomes small, as the ambient pressure increases because the diffusion of fuel spray was disturbed by a high ambient density;

- the effect of ambient pressure on atomization characteristics of SME and DME spray showed that as the ambient pressure increased, the local SMD of two sprays have decreasing patterns. The SME spray also has a larger local SMD distribution than that of DME spray. Therefore, the DME spray has a superior atomization performance compared to the SME spray under the same injection condition.

\section{ACKNOWLEDGEMENT}

This work was supported by grant No. KRF-2008-314D00056 from the Korea Research Foundation. Also, this work was supported by the Second Brain Korea 21 Project in 2007.

\section{REFERENCES}

Abdelghaffar W.A., Karimi K., Heikai M.R. (2007) Fuel spray penetration in high pressure diesel engines, SAE Tech. Paper Series 2007-01-0066.

Bosch W. (1966) The fuel rate indicator: A new measuring instrument for display of the characteristics of individual injection, $S A E$ Tech. Paper Series 660749.

Desantes J.M., Payri R., Garcia A., Manin J. (2009) Experimental Study of Biodiesel Blends' Effects on Diesel Injection Processes, Energ. Fuel. 23, 3227-3235.

Fang T., Lin Y., Foong T.M., Lee C.F. (2008) Spray and combustion visualization in an optical HSDI diesel engine operated in lowtemperature combustion mode with bio-diesel and diesel fuels, $S A E$ Tech. Paper Series 2008-01-1390. 
He C., Ge Y., Tan J., Han X. (2008) Spray properties of alternative fuels: A comparative analysis of biodiesel and diesel, Int. J. Energ. Res. 32, 1329-1338.

Kim H.J., Suh H.K., Park S.H., Lee C.S. (2008a) An experimental and numerical investigation of atomization characteristics of biodiesel, dimethyl ether, and biodiesel-ethanol blended fuel, Energ. Fuel. 22, 3, 2091-2098.

Kim H.J., Suh H.K., Lee C.S. (2008b) Numerical and experimental study on the comparison between diesel and DiMethyl Ether (DME) spray behaviors according to combustion chamber shape, Energ. Fuel. 22, 4, 2851-2860.

Lee C.S., Park S.W., Kwon S.I. (2005) An experimental study on the atomization and combustion characteristics of biodiesel-blended fuels, Energ. Fuel. 19, 5, 2201-2208.

Li J., Yoshio S., Akira N. (2001) An Experimental Study on DME Spray Characteristics and Evaporation Processes in a High Pressure, SAE Tech. Paper Series 2001-01-3635.

Payri F., Desantes M., Arregle J. (1996) Characterization of D.I. diesel sprays in high density conditions, SAE Tech. Paper Series 960774.

Pogorevc P., Kegl B., Skerget L. (2008) Diesel and Biodiesel Fuel Spray Simulations, Energ. Fuel. 22, 1266-1274.

Roisman I.V., Araneo L., Tropea C. (2007) Effect of ambient pressure on penetration of a diesel spray, Int. J. Multiphas. Flow 33, 904-920.

Sidu X., Mingfa Y., Junfeng X. (2001) An Experimental Investigation on the Spray Characteristics of Dimethyl Ether (DME), SAE Tech. Paper Series 2001-01-0142.

Sorenson S.C., Glensvig M., Abata D.L. (1998) Dimethyl ehther in diesel fuel injection system, SAE Tech.Paper Series 981159.
Teng H., McCandless J.C. (2005) Comparative study of characteristics of diesel-fuel and dimethyl-ether sprays in the engine, SAE Tech. Paper Series 2005-01-1723.

Teng H., McCandless J.C., Schneyer J.B. (2001) Thermochemical characteristics of dimethyl ether-An alternative fuel for compressionignition engines, SAE Tech. Paper Series 2001-01-0154.

Teng H., McCandless J.C., Schneyer J.B. (2002) Viscosity and lubricity of (liquid) dimethyl Ether-An alternative fuel for compression-ignition engines, SAE Tech. Paper Series 2002-01-0862.

Teng H., McCandless J.C., Schneyer J.B. (2003) Compression ignition delay (physical + chemical) of dimethyl ether - An alternative fuel for compression-ignition engines, SAE Tech. Paper Series 2003-01-0759.

Teng H., McCandless J.C., Schneyer J.B. (2004) Thermodynamic properties of dimethyl ether - An alternative fuel for compressionignition engines, SAE Tech. Paper Series 2004-01-0093.

Wu Z., Zhu Z., Huang Z. (2006) An experimental study on the spray structure of oxygenated fuel using laser-based visualization and particle image velocimetry, Fuel 85, 1458-1464.

Yamashita H., Suzuki T., Matsuoka H., Mashida M., Kitano K. (2007) Research of the DI diesel spray characteristics at high temperature and high pressure ambient, SAE Tech. Paper Series 200701-0665.

Yoon S.H., Park S.H., Lee C.S. (2008) Experimental investigation on the fuel properties of biodiesel and its blends at various temperatures, Energ. Fuel. 22, 1, 652-656.

Final manuscript received in July 2009 Published online in October 2010 